\title{
Diagnosis and Treatment of Myocardial Fibrosis in Hypertensive Heart Disease
}

\author{
Javier Díez, MD, $\mathrm{PhD}^{*}, * *$
}

\begin{abstract}
Although hypertensive heart disease (HHD) is clinically characterized by development of left ventricular hypertrophy in the absence of a cause other than arterial hypertension, changes in the composition of myocardial tissue also develop in arterial hypertension, leading to structural remodeling of the myocardium (eg, fibrosis). Myocardial fibrosis is the major determinant of diastolic dysfunction/failure in patients with HHD. Recent available data on the determination of serum concentrations of collagen-derived serum peptides, as well as quantitative analysis of echoreflectivity to address the presence of fibrosis in the myocardium of hypertensive patients, are promising. In addition, preliminary data suggest that the goal of reducing myocardial fibrosis is achievable using specific pharmacological agents in patients with HHD. (Circ J 2008; Suppl A: A-8-A-12)
\end{abstract}

Key Words: Collagen; Fibrosis; Hypertension; Hypertrophy

$\mathbf{H}$ ypertensive heart disease (HHD) can be defined as the response of the heart to the stress imposed on the left ventricle by progressively increasing arterial pressure. HHD is characterized by complex changes in myocardial composition that are responsible for the structural remodeling of the myocardium! Whereas cardiomyocyte hypertrophy leading to left ventricular hypertrophy $(\mathrm{LVH})$ is the adaptive response of the heart to pressure overload in an attempt to normalize systolic wall stress, alterations in the non-cardiomyocyte compartment of the myocardium (eg, proliferation and activation of fibroblasts, transformation of fibroblasts to myofibroblasts) can lead to fibrosis that, in turn, may facilitate the transition to heart failure and other cardiac alterations (eg, reduction of coronary flow reserve and development of arrhythmias)?,3 Therefore, because myocardial fibrosis represents the maladaptive response of the heart to arterial hypertension, strategies aimed at its detection and treatment must be developed.

\section{Pathophysiological Aspects}

An exaggerated accumulation of collagen type I and III fibers within the myocardial interstitium and surrounding intramural coronary arteries and arterioles has been consistently found in a number of studies performed in postmortem human hearts ${ }^{4-6}$ and endomyocardial human biopsies ${ }^{7-10}$ in patients with HHD (Fig 1). Hypertensive myocardial fibrosis is related to the disruption of the equilibrium between the synthesis and degradation of collagen type I and III mole-

(Received December 26, 2007; revised manuscript received May 13, 2008; accepted June 22, 2008; released online September 4, 2008)

*Division of Cardiovascular Sciences, Centre for Applied Medical Research, **Department of Cardiology and Cardiovascular Surgery, University Clinic School of Medicine, University of Navarra, Pamplona, Spain

Mailing address: Javier Díez, MD, PhD, División de Ciencias Cardiovasculares, Edificio CIMA, C/Pío XII, 55, 31008 Pamplona, Spain. E-mail: jadimar@unav.es

All rights are reserved to the Japanese Circulation Society. For permissions, please e-mail: cj@j-circ.or.jp cules, as a consequence of a number of pathologic processes mediated by mechanical, neurohormonal and cytokine routes $!^{11,12}$ Although an association has been found between severe myocardial fibrosis and left ventricular (LV) systolic dysfunction in patients with $\mathrm{HHD}_{1}^{13,14}$ the degree of myocardial fibrosis has been shown to be a critical determinant of the deterioration of some parameters used to assess LV diastolic function in these patients ${ }^{15-17}$

Diastole consists of an early, rapid filling phase related to active cardiomyocyte relaxation and a late, passive phase, which is dependent upon the elastic properties of the LV. Diastolic dysfunction refers to abnormalities in LV relaxation secondary to a reduced velocity of relaxation of hypertrophied cardiomyocytes, and a reduced LV distensibility because of increased passive stiffness of a fibrotic myocardium $!^{18}$ Therefore, diastolic dysfunction is the hemodynamic hallmark of HHD and heart failure with preserved ejection fraction, and severe diastolic dysfunction is characteristic of patients with HHD in the absence of advanced ischemic heart disease $!^{19}$

\section{Diagnosis of Myocardial Fibrosis}

Although microscopic examination of cardiac biopsies is the most reliable method of documenting and measuring myocardial fibrosis, it is invasive and not useful for widescale application, as well as being subject to sampling error. Thus, the development of noninvasive methods to indicate the presence of LV fibrosis in hypertensive patients would have a broad application.

\section{Non-Invasive Physical Methods}

Ultrasonic tissue characterization can identify and characterize the physical or physiological state of the myocardium based on analysis of the interactions between ultrasound and the tissue ${ }^{20}$ It is based on the principle that the interaction of ultrasound waves with normal myocardial tissue results in reflected ultrasonic signals that exhibit characteristics different from those obtained when ultrasound interacts with abnormal tissue (eg, fibrotic tissue)? ${ }^{2}$ These characteristics are amenable to quantification (one of 

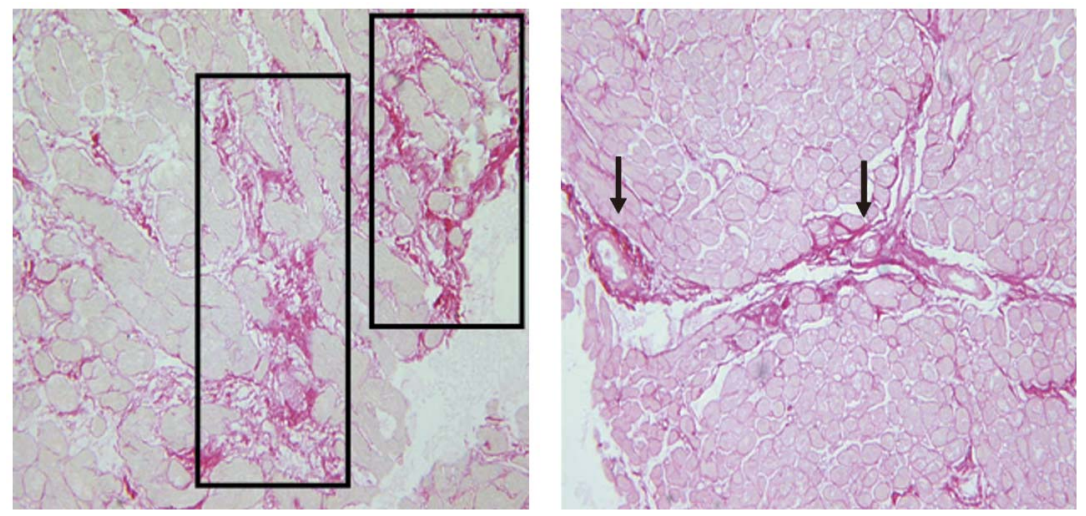

Fig 1. Histological section of a myocardial specimen biopsy from a patient with hypertensive heart disease showing interstitial fibrosis (Left panel, fibrosis signaled within the rectangles) and perivascular fibrosis (Right panel, fibrosis signaled by arrows). Picrosirius red stain; $\times 20$ (adapted from reference 17).

Baseline

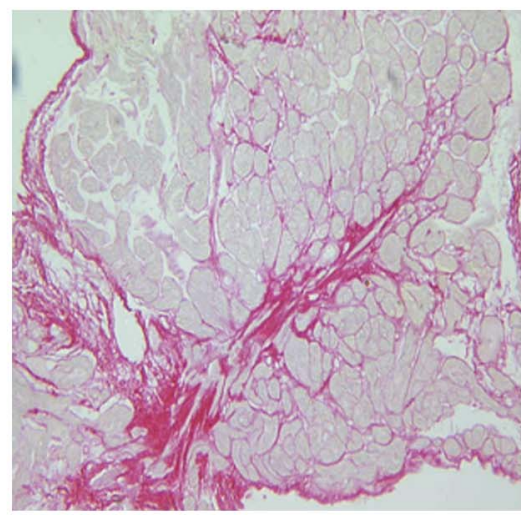

CVF (\%)

PICP $(\mu \mathrm{g} / \mathrm{L})$

$\mathbf{K}_{\mathbf{L V}}(\mathrm{mmHg} / \mathrm{ml})$
8.02

157

0.26
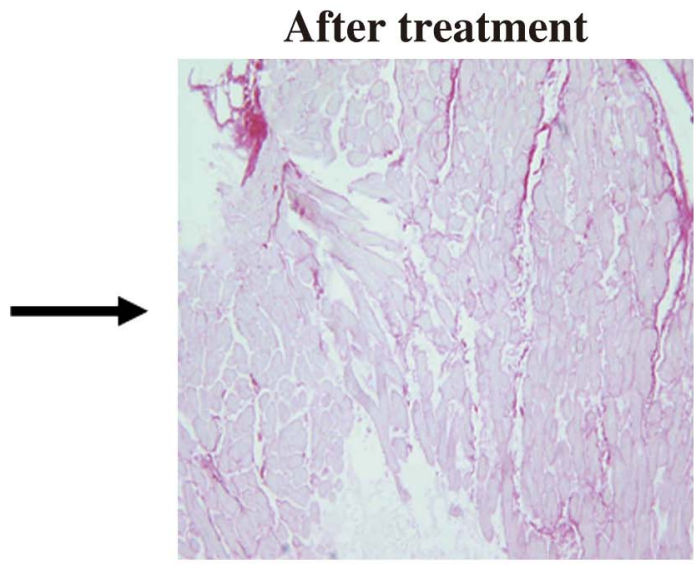

3.15

98

Fig 2. Histological section of a myocardial specimen biopsy from a patient with hypertensive heart disease before (Left panel) and after (Right panel) 1 year of treatment with the angiotensin type 1 receptor blocker losartan. Picrosirius red stain; $\times 20$. CVF, myocardial collagen volume fraction; PICP, carboxy-terminal propeptide of procollagen type I; KLV, left ventricular chamber stiffness (adapted from reference 17).

the approaches being the measurement of tissue-integrated backscatter), that defines the myocardial structure and functional attributes. In this regard, an association between alterations in echoreflectivity, namely diminution in the cyclic variation of the backscatter signal, and an increase in fibrous tissue has been shown in the hearts of hypertensive patients?,22

\section{Non-Invasive Biochemical Methods}

Emerging experimental and clinical experience holds promise for the determination of various serum peptides derived from the metabolism of collagen type I in arterial hypertension ${ }^{23}$ More specifically, the serum concentrations of the carboxy-terminal propeptide of procollagen type I or PICP (a peptide that is cleaved from procollagen type I during the synthesis of fibril-forming collagen type I by the enzyme procollagen type I carboxy-terminal proteinase or PCPase) has been shown to be associated with both the volume of myocardial tissue occupied by collagen fibers ${ }^{10}$ and the activation of the enzyme PCPase ${ }^{24}$ in patients with HHD. In addition, changes in serum PICP concentration induced by antihypertensive treatment have been shown to be associated with changes in the volume of myocardial tissue occupied by collagen fibers (Fig 2)! 17,25 It has been recently found that the concentration of PICP is significantly higher in the coronary blood than in the peripheral blood of patients with HHD, but not in normotensive subjects! $!^{4}$ In the same study, PICP measured in peripheral blood was found to be associated with PICP measured in coronary blood and with the amount of collagen type I fibers present in the myocardium (as assessed immunohistochemically) ${ }^{14}$ Collectively, these findings suggest that circulating PICP is a reliable index of the extent of collagen type I-dependent fibrosis in the human hypertensive myocardium.

Interestingly, an association has been found between diminished cyclic variation of backscatter and an increased serum concentration of PICP in hypertensive patients? 26,27 Thus, the combination of these 2 parameters may be useful for the noninvasive diagnosis of myocardial fibrosis associated with hypertension.

\section{Treatment of Myocardial Fibrosis}

To reduce the extent of collagen accumulation in the LV may be relevant in both improving the diagnosis of HHD and optimizing the prevention of heart failure and adverse 
cardiovascular events in patients with this condition.28

Brilla et al showed that treatment with the angiotensinconverting enzyme inhibitor, lisinopril, but not with the diuretic, hydrochlorotiazide, reduced myocardial fibrosis in patients with HHD, independent of blood pressure control and $\mathrm{LVH}$ regression, and that this was associated with improved LV diastolic function. ${ }^{29}$ My group has shown that treatment with the angiotensin II type 1 (AT1) receptor antagonist, losartan, was associated with inhibition of collagen type I synthesis and regression of myocardial fibrosis in patients with essential hypertension, whereas hypertensive patients treated with the calcium-channel blocker, amlodipine, did not show significant changes in collagen type I metabolism or myocardial fibrosis 25 Interestingly, the effect of the 2 agents on blood pressure was similar throughout the treatment period. It has also been reported that the ability of losartan to induce regression of severe myocardial fibrosis is independent of its capacity to reduce blood pressure or LV mass, but is associated with a diminution of myocardial stiffness in patients with HHD (Fig 2)! 17

Recently, López et al reported that the loop diuretic, torasemide, but not furosemide, significantly reduced cardiac fibrosis in biopsy specimens from hypertensive patients with symptomatic heart failure $3^{0}$ This finding is in agreement with recent experimental data obtained in rats with induced heart failure 31,32 Of interest, the antifibrotic effect of torasemide was shown to be associated with its ability to inhibit PCPase activation in the myocardium of heart failure patients? 24 Interestingly, torasemide, but not furosemide, has been reported to prevent cardiac uptake of aldosterone in heart failure patients ${ }^{33}$ and to block the binding of the hormone to the mineralocorticoid receptor ${ }^{34}$ Because aldosterone has been found to increase PCPase activity in cultured rat cardiac fibroblasts 35 it is possible that the antifibrotic effect of torasemide in heart failure patients is related to interference with the fibrogenic actions of aldosterone at the PCPase level.

\section{Future Developments}

\section{At the Diagnostic Level}

Magnetic resonance imaging is a promising technique for characterizing the composition of the myocardium. Tissue characterization with the contrast agent gadolinium is well validated and provides insights to the quantification of ischemic and nonischemic fibrosis 36 In the setting of chronic myocardial damage, exaggerated collagen deposition expands the interstitial space, which leads to increased gadolinium concentration and therefore late gadolinium enhancement ${ }^{37}$ In this regard, it has been reported recently that late gadolinium enhancement had a strong correlation with histologically assessed myocardial fibrosis in patients with arrhythmogenic right ventricular cardiomyopathy 38 Therefore, image texture analysis appears to be a fertile area for research into the noninvasive assessment of myocardial fibrosis in HHD.

Particularly exciting are the emerging molecular imaging techniques incorporating the use of targeted and activatable molecular probes with the modalities of SPECT, PET, and optical imaging to detect adverse remodeling that represents changes at the tissue, cellular or molecular level. ${ }^{39}$ Some of these probes are of interest for the assessment of the dynamic balance between synthesis and degradation of collagen, with a stable yet dynamic turnover in the normal heart. For example, myocardial collagen degradation is regulated through the action of matrix metalloproteinases (MMP). Both ${ }^{111}$ indium- and $99 \mathrm{mTc}$-radiolabeled ligands have been synthesized and used to assess MMP activity in infarcted myocardium by planar and SPECT imaging in a murine model ${ }^{40}$ Even more, a near-infrared fluorescent probe for evaluation of MMP activity was synthesized and evaluated recently in an experimental model of myocardial infarction.1

\section{At the Pharmacogenomic Level}

The knowledge of polymorphisms in genes that potentially influence pharmacodynamic mechanisms would allow the identification of individuals who are likely to have beneficial responses to treatment with a particular drug. Based on various lines of evidence suggesting that systemically and/or locally produced angiotensin II may participate in the development of myocardial fibrosis in HHD via activation of AT1 receptors, 42 my group investigated the potential role of the A1166C polymorphism of the AT1 receptor gene 43 Patients with HHD were studied before and after 1 year of treatment with losartan or the $\beta$-blocker atenolol. Baseline PICP was significantly increased in AA hypertensive subjects compared with AC/CC hypertensive patients. Confounding factors were similar in the 2 subgroups. Administration of losartan was associated with a significant reduction in PICP in AA hypertensive, but not AC/CC hypertensive, patients. Treatment with atenolol did not change PICP in either subgroup. Blood pressure was reduced to the same extent in the 4 treatment subgroups. If these results were confirmed by larger, prospective, double-blind studies, the genotype of the A1166C polymorphism of the AT1 receptor gene could be a useful indicator for antihypertensive drug therapy aimed at reducing myocardial fibrosis in patients with HHD

\section{At the New Therapeutic Strategies Level}

Recent experimental work has been conducted to examine alternative potential therapeutic strategies. It has been reported that the antiinflammatory drug tranilast 44 and the natural inhibitor of hematopoietic stem cell proliferation, Ac-SDKP 45 reduce myocardial inflammation and fibrosis in rats with experimental hypertension through mechanisms probably related to inhibition of transforming growth factor- $\beta$. Fenofibrate, a peroxisome proliferator-activated receptor- $\alpha$ (PPAR- $\alpha$ ) agonist, reportedly reduces fibrosis in the heart of rats in different models of experimentallyinduced hypertension. ${ }^{46-49}$ It is possible that the antifibrotic action of PPAR- $\alpha$ stimulation is the result of increased repression of pro-inflammatory genes $(\mathrm{eg}, \mathrm{NF}-\kappa \mathrm{B}) 5^{0}$ The inhibitor of the ubiquitin-proteasome system, MG132, has been shown to suppress fibrillar collagen expression in isolated fibroblasts and to reduce myocardial fibrosis in spontaneously hypertensive rats $?^{51}$ Although the exact mechanisms underlying these effects remain to be elucidated, a complex interplay of transcription factors has been implicated in the regulation of collagen promoter, involving several substrates of proteasomal protein degradation, such as $\mathrm{NF}-\kappa \mathrm{B}, \mathrm{AP}-1, \mathrm{SP}-1$, and $\mathrm{p} 539^{52}$ It has been shown that statins prevent the cardiac fibrosis that develops in different rat models of hypertensions ${ }^{5-55}$ Preliminary data suggest that the antifibrotic effect of statins is the result of a direct action on signals that cause fibroblast growth and activation56 Finally, recent findings demonstrate that activation and overexpression of adenylyl cyclase inhibits adult rat 
myofibroblast formation and collagen synthesis ${ }^{57}$ thus providing a rationale for strategies aimed at increasing cyclic AMP levels in cardiac fibroblasts. Collectively, all these findings open new and attractive approaches to interfering with myocardial fibrosis, although clearly, more extensive work is required to justify their possible application to the treatment of HHD.

\section{Conclusions}

The time has come to revisit the current management of HHD that is simply focused on detecting LVH and controlling blood pressure to reduce LV mass. In patients with $\mathrm{HHD}$, it is necessary to develop new approaches aimed at assessing and repairing changes in collagen turnover that predispose to fibrosis and contribute importantly to the functional and structural abnormalities that cause progressive cardiac dysfunction. Recent findings suggest that monitoring circulating markers of collagen type I turnover in combination with echocardiographic assessment of myocardial texture might provide important diagnostic information with respect to ongoing adverse myocardial fibrosis in patients with HHD. In addition, preliminary data suggest that using specific therapies targeting the regulation or activation of the enzymes responsible for fibrillar collagen turnover homeostasis might represent novel opportunities to modify the natural progression of HHD. Collectively, all this information sets the stage for large and long-term clinical trials aimed at determining whether the assessment and reversal of myocardial fibrosis in HHD are definitively associated with beneficial effects on the patient's prognosis.

\section{Disclosure}

This review was conducted independently; no company or institution supported it financially.

\section{References}

1. Díez J. Hypertensive heart disease. In: Lip GYH, Hall JE, editors. Comprehensive hypertension. Philadelphia, PA: Mosby Elsevier; 2007; 621-631.

2. Díez J, González A, López B, Querejeta R. Mechanisms of disease: Pathologic structural remodeling is more than adaptive hypertrophy in hypertensive heart disease. Nat Clin Pract Cardiovasc Med 2005; 2: 209-216.

3. Díez J, López B, González A, Querejeta R. Clinical aspects of hypertensive myocardial fibrosis. Curr Opin Cardiol 2001; 16: 328-335.

4. Tanaka M, Fujiwara H, Onodera T, Wu DJ, Hamashima Y, Kawai C. Quantitative analysis of myocardial fibrosis in normals, hypertensive hearts, and hypertrophic cardiomyopathy. Br Heart J 1986; 55: 575 581

5. Olivetti G, Melissari M, Balbi T, Quaini F, Cigola E, Sonnenblick $\mathrm{EH}$, et al. Myocyte cellular hypertrophy is responsible for ventricular remodeling in the hypertrophied heart of middle aged individuals in the absence of cardiac failure. Cardiovasc Res 1994; 28: 1199 1208.

6. Rossi MA. Pathologic fibrosis and connective tissue matrix in left ventricular hypertrophy due to chronic arterial hypertension in humans. J Hypertens 1998; 16: 1031-1041.

7. Ciulla M, Paliotti R, Hess DB, Tjahja E, Campbell SE, Magrini F, et al. Echocardiographic patterns of myocardial fibrosis in hypertensive patients: Endomyocardial biopsy versus ultrasonic tissue characterization. J Am Soc Echocardiogr 1997; 10: 657-664.

8. Schwartzkopff B, Brehm M, Mundhenke M, Strauer BE. Repair of coronary arterioles after treatment with perindopril in hypertensive heart disease. Hypertension 2000; 36: 220-225.

9. Brilla CG, Funck RC, Rupp H. Lisinopril-mediated regression of myocardial fibrosis in patients with hypertensive heart disease. Circulation 2000; 102: 1388-1393.

10. Querejeta R, Varo N, López B, Larman M, Artiñano E, Etayo JC, et al. Serum carboxy-terminal propeptide of procollagen type $\mathrm{I}$ is a marker of myocardial fibrosis in hypertensive heart disease. Circulation 2000; 101: 1729-1735.

11. Díez J. Mechanisms of cardiac fibrosis in hypertension. J Clin Hypertens 2007; 9: 546-550.

12. Berk BC, Fujiwara K, Lehoux S. ECM remodeling in hypertensive heart disease. J Clin Invest 2007; 117: 568-575.

13. McLenachan JM, Dargie JH. Ventricular arrhythmias in hypertensive left ventricular hypertrophy: Relation to coronary artery disease, left ventricular dysfunction, and myocardial fibrosis. Am J Hypertens 1990; 3: 735-740.

14. Querejeta R, López B, González A, Sánchez E, Larman M, Martínez Ubago JL, et al. Increased collagen type I synthesis in patients with heart failure of hypertensive origin: Relation to myocardial fibrosis. Circulation 2004; 110: $1263-1268$.

15. Sugihara N, Genda A, Shimizu M, Suematu T, Kita Y, Horita Y, et al. Quantitation of myocardial fibrosis and its relation to function in essential hypertension and hypertrophic cardiomyopathy. Clin Cardiol 1988; 11: 771-778.

16. Ohsato K, Shimizu M, Sugihara M, Konishi K, Takeda R. Histopathological factors related to diastolic function in myocardial hypertrophy. Jpn Circ J 1992; 56: 325-333.

17. Díez J, Querejeta R, López B, González A, Larman M, Martínez Ubago JL. Losartan-dependent regression of myocardial fibrosis is associated with reduction of left ventricular chamber stiffness in hypertensive patients. Circulation 2002; 105: 2512-2517.

18. Brower GL, Gardner JD, Forman MF, Murray DB, Voloshenyuk T, Levick SP, et al. The relationship between myocardial extracellular matrix remodeling and ventricular function. Eur J Cardiothor Surg 2006; 30: 604-610.

19. Wright JW, Mizutani S, Harding JW. Pathways involved in the transition from hypertension to hypertrophy to heart failure: Treatment strategies. Heart Fail Rev 2008; 13: 367-375.

20. Tamirisa PK, Holland MR, Miller JG, Pérez JE. Ultrasonic tissue characterization: Review of an approach to assess hypertrophic myocardium. Echocardiography 2001; 7: 593-597.

21. Kerut EK, Given M, Giles TD. Review of methods for texture analysis of myocardium from echocardiographic images: A means of tissue characterization. Echocardiography 2003; 20: 727-736.

22. Picano E, Pelosi G, Marzilli M, Lattanzi F, Benassi A, Landini L, et al. In vivo quantitative ultrasonic evaluation of myocardial fibrosis in humans. Circulation 1990; 81: 58-64.

23. López B, González A, Querejeta R, Díez J. The use of collagenderived serum peptides for the clinical assessment of hypertensive heart disease. J Hypertens 2005; 23: 1445-1451.

24. López B, González A, Beaumont J, Querejeta R, Larman M, Díez J. Identification of a potential cardiac antifibrotic mechanism of torasemide in patients with chronic heart failure. $\mathrm{J} \mathrm{Am} \mathrm{Coll} \mathrm{Cardiol}$ 2007; 50: $859-867$.

25. López B, Querejeta R, Varo N, González A, Larman M, Martínez Ubago JL, et al. Usefulness of serum carboxy-terminal propeptide of procollagen type I in assessment of the cardioreparative ability of antihypertensive treatment in hypertensive patients. Circulation 2001; 104: $286-291$

26. Maceira AM, Barba J, Varo N, Beloqui O, Díez J. Ultrasonic backscatter and serum marker of cardiac fibrosis in hypertensives. Hypertension 2002; 39: 923-928.

27. Lin YH, Shiau YC, Yen RF, Lin LC, Wu CC, Ho YL, et al. The relation between myocardial cyclic variation of integrated backscatter and serum concentrations of procollagen propeptides in hypertensive patients. Ultrasound Med Biol 2004; 30: 885-891.

28. Weber KT. Cardioreparation in hypertensive heart disease. Hypertension 2001; 38: 588-591.

29. Brilla CG, Funck RC, Rupp H. Lisinopril-mediated regression of myocardial fibrosis in patients with hypertensive heart disease. Circulation 2000; 102: 1388-1393.

30. López B, Querejeta R, González A, Sánchez E, Larman M, Díez J. Effect of loop diuretics on myocardial fibrosis and collagen type I turnover in chronic heart failure. J Am Coll Cardiol 2004; 43: 2028 2035.

31. Veeraveedu PT, Watanabe K, Ma M, Thandavarayana RA, Palaniyandi SS, Yamaguchi K, et al. Comparative effects of torasemide and furosemide in rats with heart failure. Biochem Pharmacol 2008; 75: $649-659$.

32. Veeraveedu PT, Watanabe K, Ma M, Palaniyandi SS, Yamaguchi K, Suzuki K, et al. Torasemide, a long-acting loop diuretic, reduces the progression of myocarditis to dilated cardiomyopathy. Eur J Pharmacol 2008; 581: 121-131.

33. Tsutamoto T, Sakai H, Wada A, Ishikawa C, Ohno K, Fujii M, et al. Torasemide inhibits transcardiac extraction of aldosterone in patients with congestive heart failure. J Am Coll Cardiol 2004; 44: 2252 
2253.

34. Uchida T, Yamanaga K, Nishikawa M, Ohtaki Y, Kido H, Watanabe M. Anti-aldosteronic effect of torasemide. Eur J Pharmacol 1991; 205: $145-150$.

35. Shalitin N, Schlesinger H, Levy MJ, Kessler E, Kessler-Icekson G. Expression of procollagen C-proteinase enhancer in cultured rat heart fibroblasts: Evidence for co-regulation with type I collagen. $J$ Cell Biochem 2003; 90: 397-407.

36. Moon JC, Prasad SK. Cardiovascular magnetic resonance and the evaluation of heart failure. Curr Cardiol Rep 2005; 7: 39-44.

37. Vöhringer M, Mahrholdt H, Yilmaz A, Sechtem U. Significance of late gadolinium enhancement in cardiovascular magnetic resonance imaging (CMR). Herz 2007; 32: 129-137.

38. Tandri H, Saranathan M, Rodriguez ER, Martinez C, Bomma C, Nasir $\mathrm{K}$, et al. Noninvasive detection of myocardial fibrosis in arrhythmogenic right ventricular cardiomyopathy using delayed-enhancement magnetic resonance imaging. J Am Coll Cardiol 2005; 45: 98 103.

39. Shirani J, Dilsizian V. Molecular imaging in heart failure. Curr Opin Biotechnol 2007; 18: $65-72$.

40. Su H, Spinale FG, Dobrucki LW, Song J, Hua J, Sweterlitsch S, et al. Noninvasive targeted imaging of matrix metalloproteinase activation in a murine model of postinfarction remodeling, Circulation 2005; 112: $3157-3167$.

41. Chen J, Tung CH, Allport J, Chen S, Weissleder R, Huang PL. Nearinfrared fluorescent imaging of matrix metalloproteinase activity after myocardial infarction, Circulation 2005; 111: 1800-1805.

42. González A, López B, Querejeta R, Díez J. Regulation of myocardial fibrillar collagen by angiotensin II: A role in hypertensive heart disease? J Mol Cell Cardiol 2002; 34: 1585-1593.

43. Díez J, Laviades C, Orbe J, Zalba G, López B, González A, et al. The A1166C polymorphism of the AT1 receptor gene is associated with collagen type I synthesis and myocardial stiffness in hypertensives. J Hypertens 2003; 21: 2085-2092.

44. Kagitani S, Ueno H, Hirade S, Takahashi T, Takata M, Inoue H. Tranilast attenuates myocardial fibrosis in association with suppression of monocyte/macrophage infiltration in DOCA/salt hypertensive rats. J Hypertens 2004; 22: $1007-1015$.

45. Rasoul S, Carretero OA, Peng H, Cavasin MA, Zhuo J, SanchezMendoza A, et al. Antifibrotic effect of Ac-SDKP and angiotensinconverting enzyme inhibition in hypertension. J Hypertens 2004; 22: 593-603.

46. Ogata T, Miyauchi T, Sakai S, Takanashi M, Irukayama-Ytomobe Y, Yamaguchi I. Myocardial fibrosis and diastolic dysfunction in deoxycorticosterone acetate-salt hypertensive rats is ameliorated by the peroxisome proliferators-activated receptor-alpha activator fenofibrate, partly by suppressing inflammatory responses associated with the nuclear factor-kappa-B pathway. J Am Coll Cardiol 2004; 43: 1481 1488.

47. Iglarz M, Touyz RM, Viel MC, Paradis P, Amiri F, Diep QN, et al. Peroxisome proliferator-activated receptor- $\alpha$ and receptor- $\gamma$ activators prevent cardiac fibrosis in mineralocortioid-dependent hypertension. Hypertension 2003; 42: 737-743.

48. Diep QN, Benkirane K, Amiri F, Cohn JS, Endemann D, Schiffrin EL. PPAR $\alpha$ activator fenofibrate inhibits myocardial inflammation and fibrosis in angiotensin II-infused rats. J Mol Cell Cardiol 2004; 36: $295-304$.

49. Ogata T, Miyauchi T, Sakai S, Irukayama-Tomobe Y, Goto K, Yamaguchi I. Stimulation of peroxisome-proliferator-activated receptor $\alpha(\operatorname{PPAR} \alpha)$ attenuates cardiac fibrosis and endothelin-I production in pressure-overloaded rat hearts. Clin Sci 2002; 103(Suppl 48): 284S-288S

50. Schiffrin EL, Amiri F, Benkirane K, Iglarz M, Diep QN. Peroxisome proliferator-activated receptors: Vascular and cardiac effects in hypertension. Hypertension 2003; 42: 664-668.

51. Meiners S, Hocher B, Weller A, Laule M, Stangl V, Guenther C, et al. Downregulation of matrix metalloproteinases and collagens and suppression of cardiac fibrosis by inhibition of the proteasome. Circulation 2004; 44: 471-477.

52. Ghosh AK. Factors involved in the regulation of type I collagen gene expression: Implications in fibrosis. Exp Biol Med 2002; 227: $301-$ 314.

53. Dechend R, Fiebeler A, Park JK, Muller DN, Theuer J, Mervaala E, et al. Amelioration of angiotensin II-induced cardiac injury by a 3hydroxy-3-methylglutaryl coenzyme A reductase inhibitor. Circulation 2001; 104: 576-581.

54. Hasegawa H, Yamamoto R, Takano H, Mizukami M, Asakawa M, Nagai T, et al. 3-Hydroxy-3-methylglutaryl coenzyme A reductase inhibitors prevent the development of cardiac hypertrophy and heart failure in rats. J Mol Cell Cardiol 2003; 35: 953-960.

55. Bezerra DG, Mandarim-de-Lacerda CA. Beneficial effect of simvastatin and pravastatin treatment on adverse cardiac remodeling and glomeruli loss of spontaneously hypertensive rats. Clin Sci 2005; 108: $349-355$.

56. Porter KE, Turner NA, O'Regan DJ, Balmforth AJ, Ball SG. Simvastatin reduces human atrial myofibroblast proliferation independently of cholesterol lowering via inhibition of RhoA. Cardiovasc Res 2004; 61: 745-755.

57. Swaney JS, Roth DM, Olson ER, Naugle JE, Meszaros JG, Insel PA. Inhibition of cardiac myofibroblast formation and collagen synthesis by activation and overexpression of adenylyl cyclase. Proc Natl Acad Sci USA 2005; 102: 437-442. 